\title{
The Low-Density Lipoprotein Receptor-Related Protein Is a Pro-Survival Receptor in Schwann Cells: Possible Implications in Peripheral Nerve Injury
}

\author{
W. Marie Campana, ${ }^{1}$ Xiaoqing Li, ${ }^{1}$ Nikola Dragojlovic, ${ }^{2}$ Julie Janes, ${ }^{1}$ Alban Gaultier, ${ }^{2}$ and Steven L. Gonias ${ }^{2}$ \\ ${ }^{1}$ Departments of Anesthesiology and ${ }^{2}$ Pathology, University of California, San Diego School of Medicine, La Jolla, California 92093-0629
}

\begin{abstract}
Schwann cells undergo phenotypic modulation in peripheral nerve injury. In the adult rodent, Schwann cells are resistant to deathpromoting challenges. The responsible receptors and signaling pathways are incompletely understood. In this study, we demonstrate that low-density lipoprotein receptor-related protein-1 (LRP-1) is expressed in adult sciatic nerve. After crush injury, LRP-1 is lost from the axoplasm and substantially upregulated in Schwann cells. Increased LRP-1 mRNA expression was observed locally at the injury site in multiple forms of sciatic nerve injury, including crush injury, chronic constriction injury, and axotomy. Endogenously produced tumor necrosis factor- $\alpha(T N F-\alpha)$ was mostly responsible for the increase in LRP-1 expression; this activity was reproduced by direct injection of TNF- $\alpha$ into injured nerves in the TNF- $\alpha$ gene knock-out mouse. TNF receptor II was primarily involved. TNF- $\alpha$ also increased LRP-1 mRNA in Schwann cells in primary culture. Silencing of Schwann cell LRP-1 with siRNA decreased phosphorylated Akt and increased activated caspase-3. Equivalent changes in cell signaling were observed in LRP-1-deficient murine embryonic fibroblasts. Schwann cell death was induced in vitro by serum withdrawal or TNF- $\alpha$, to a greater extent when LRP-1 was silenced. Schwann cell death was induced in vivo by injecting the LRP-1 antagonist, receptor-associated protein, into axotomy sites in adult rats. These results support a model in which LRP-1 functions as a pro-survival receptor in Schwann cells.
\end{abstract}

Key words: Schwann cell; peripheral nerve injury; low-density lipoprotein receptor-related protein; tumor necrosis factor- $\alpha$; apoptosis; phosphatidylinositol 3-kinase

\section{Introduction}

Schwann cells undergo phenotypic modulation during development and in response to injury. When nerve injury occurs in newborn animals, immature Schwann cells undergo apoptosis because they depend on survival factors released from axons such as $\beta$-neuregulin (Jessen and Mirsky, 2005). The low-affinity neurotrophin receptor, $\mathrm{p} 75^{\mathrm{NTR}}$, which is activated by nerve growth factor, mediates immature Schwann cell death in axotomy (Syroid et al., 2000). The proinflammatory cytokine, tumor necrosis factor- $\alpha$ (TNF- $\alpha$ ), also promotes immature Schwann cell death (Boyle et al., 2005).

As the peripheral nerve matures, Schwann cells form relationships with axons and acquire the ability to ensure their own survival by generating autocrine survival circuits. In the adult rat, sciatic nerve axotomy does not induce Schwann cell death (Grinspan et al., 1996). Implicated autocrine survival factors include platelet-derived growth factor (PDGF), neurotrophin-3, and insulin-like growth factor-II (Meier et al., 1999).

\footnotetext{
Received March 31, 2006; revised Sept. 13, 2006; accepted Sept. 17, 2006.
}

This work was supported by National Institutes of Health Grants R01 NS-41983 (W.M.C.) and R01 HL-60551 (S.L.G.). We thank Jenny Dolkas for excellent technical support and Sanja Arandjelovic for assistance with RAP ligand blots.

Correspondence should be addressed to Dr. W. Marie Campana, Department of Anesthesiology (0629), University of California, San Diego, 9500 Gilman Drive, MTF 445, La Jolla, CA 92093-0629. E-mail: wcampana@ucsd.edu. DOI:10.1523/JNEUROSCI.2709-06.2006

Copyright $\odot 2006$ Society for Neuroscience $\quad$ 0270-6474/06/2611197-11\$15.00/0
The low-density lipoprotein receptor-related protein-1 (LRP-1) is a member of the low-density lipoprotein (LDL) receptor gene family expressed by multiple cell types, including neurons and astrocytes (Moestrup et al., 1992; Wolf et al., 1992). LRP-1 is synthesized as a $600 \mathrm{kDa}$ transmembrane protein and processed by a furin-like protease into its mature 2-chain form (Willnow et al., 1996). LRP-1 was initially identified as an endocytic receptor for apolipoprotein E (Kowal et al., 1989) and the protease inhibitor $\alpha_{2}$-macroglobulin (Strickland et al., 1990); however, over 40 LRP-1 ligands are now known, including proteases, protease inhibitors, growth factors, matrix proteins, and toxins (Strickland et al., 2002).

The cytoplasmic tail of LRP-1 contains NPXY motifs that bind signaling adaptor proteins, including Shc, JIP, Dab-1, Fe65, and CED-6/GULP (Gotthardt et al., 2000; Kinoshita et al., 2001; Su et al., 2002). Adaptor protein binding is regulated by tyrosine phosphorylation of the NPXY motifs (Newton et al., 2005). Binding of Dab-1 to apoER2 and the very low-density lipoprotein (VLDL) receptor, which are related to LRP-1, promotes activation of phosphatidylinositol 3-kinase (PI3K) (Bock et al., 2003). Binding of JIP to a chimeric receptor that includes the cytoplasmic tail of LRP-1 prevents translocation of activated c-Jun N-terminal protein kinase (JNK) to the nucleus (Lutz et al., 2002). By regulating cell signaling, LRP-1 may control cell survival. In the mouse, LRP-1 gene deletion is embryonic lethal (Herz et al., 1992).

In this study, we examined the role of LRP-1 in peripheral 
nerve injury. We show that LRP-1 is expressed in adult sciatic nerve. In response to nerve injury or locally administered TNF- $\alpha$, LRP-1 expression by Schwann cells is substantially increased. Schwann cells in primary culture also express increased LRP-1 in response to TNF- $\alpha$. When LRP-1 is silenced in Schwann cells, with siRNA, the activity of the PI3K-Akt pathway is decreased and caspase- 3 is activated. The same cells also demonstrate increased cell death in response to serum deprivation or TNF- $\alpha$. Inhibiting LRP-1 in the axotomized nerve by direct injection of receptor-associated protein (RAP) promotes Schwann cell death in vivo. We propose that LRP-1 functions as a pro-survival receptor in Schwann cells, capable of regulating neuropathophysiology in the injured peripheral nerve.

\section{Materials and Methods}

Antibodies and reagents. TaqMan primers and probes for rat LRP-1, protein $0(\mathrm{P} 0)$, and $\mathrm{p} 75^{\mathrm{NTR}}$ were designed by Oligo 6.8 software (Molecular Biology Insights, Cascade, $\mathrm{CO}$ ). Rat cyclophilin primers and probes have been described previously (Macdonald et al., 2001) and were synthesized by Biosearch Technologies (Novato, CA). Primers and probes for mouse LRP-1 and glyceraldehyde-3-phosphate dehydrogenase (GAPDH) were purchased from ABI (Foster City, CA). $\beta$-actin monoclonal antibody was purchased from Sigma (St Louis, MO). Polyclonal antibody that specifically recognizes the cleaved, activated form of caspase- 3 was purchased from Cell Signaling Technologies (Danvers, MA). Monoclonal antibody $11 \mathrm{H} 4$, which recognizes the $85 \mathrm{kDa}$ LRP-1 light chain, was purified from conditioned medium of the hybridoma available from the American Type Culture Collection (ATCC; Manassas, VA). Polyclonal antibody that recognizes the axoplasm marker, protein gene product 9.5 (PGP9.5), was purchased from Chemicon (Temecula, CA). Recombinant TNF- $\alpha$ was from R \& D Systems (Minneapolis, MN). The PI3K inhibitor, LY294002, was purchased from Calbiochem (La Jolla, CA). Affinitypurified polyclonal antibody that specifically recognizes the phosphorylated form of Akt was purchased from Promega (Madison, WI). Mouse monoclonal antibody that detects total Akt was purchased from Upstate Biotechnologies (Lake Placid, NY). Murine embryonic fibroblasts (MEFs) that are genetically deficient in LRP-1 (MEF-2 cells) and LRP-1positive MEFs [pseudomonas exotoxin A (PEA)-10 cells], which were cloned from the same MEF culture heterozygous for LRP-1 gene disruption, after selection with pseudomonas exotoxin A, were obtained from the ATCC (Willnow and Herz, 1994). RAP was expressed as a glutathione-S-transferase fusion protein (GST-RAP) as described previously (Herz et al., 1991). GST-RAP functions as an antagonist of LRP-1 ligand binding (Strickland et al., 2002). As a control, we expressed GST in bacteria transformed with the empty vector, pGEX-2T. GST-specific antibody was from Amersham (Piscataway, NJ).

Nerve injury model systems. Adult female Sprague Dawley rats (250 g), neonatal rats (20 g) from Harlan Laboratories (San Diego, CA), TNF- $\alpha$ gene knock-out mice in the B6;129SF2/J genetic background (20 g), wildtype mice in the B6;129SF2/J genetic background; TNF receptor I (TNFRI) gene knock-out mice in the C57BL/6J genetic background (20 g); TNFRII gene knock-out mice in C57BL/6J genetic background; and wild-type C57BL/6J mice were housed in pairs with a $12 \mathrm{~h} \mathrm{light/dark}$ cycle and ad libitum access to food and water. Adult rats and mice were anesthetized with isoflurane (IsoSol; VedCo, St. Joseph, MO) during surgeries and were killed by intraperitoneal injection of an overdose of anesthetic mixture containing ketamine $(60 \mathrm{mg} / \mathrm{kg}$; Phoenix Scientific, St Joseph, MO), xylazine $(6.4 \mathrm{mg} / \mathrm{kg}$; Boerhinger Pharmaceutical, St. Joseph, MO), and acepromazine (1.2 mg/kg; Fermenta, Animal Health, Kansas City, MO). Neonatal animals were anesthetized in an ice-water bath as described previously (Grinspan et al., 1996). All procedures were performed according to protocols approved by the University of California, San Diego, and the Veterans Affairs Healthcare System Committee on Animal Research, and conform to the National Institutes of Health Guidelines for Animal Use.

Sciatic nerve crush injury experiments were performed in adult rats. Nerves were crushed twice for $2 \mathrm{~s}$ at the sciatic nerve notch using flat forceps, as described previously (Myers et al., 2003). Nerve tissue distal to the injury site $(0.5 \mathrm{~cm})$ and L5 dorsal root ganglion (DRG) were collected at $0,1,7$, and $14 \mathrm{~d}$ after injury. Naive nerve and L5 DRG were collected from control animals that underwent sham operation.

In chronic constriction injury (CCI) experiments, TNF- $\alpha-/-$, TNFRI $-/-$, TNFRII-/ - , and control mice were studied. The sciatic nerve was exposed unilaterally at the mid-thigh level. Three 4.0 chromic gut ligatures were placed around the nerve with $1 \mathrm{~mm}$ spacing. The ligatures were tied until they just slightly constricted the diameter of the nerve (Bennett and Xie, 1988) and a short twitch was seen in the respective hind limb. This caused a 50\% reduction in nerve blood flow and Wallerian degeneration (Myers et al., 1993). In some experiments, $2 \mu$ l of TNF- $\alpha(1.0 \mu \mathrm{M})$ or vehicle was injected immediately into the CCI site before tightening the ligatures. The muscle layer was closed using a silk suture and the skin was closed using surgical staples. At 1 and $3 \mathrm{~d}$ after injury, $1 \mathrm{~cm}$ of nerve tissue was collected, which included the injury site and tissue distal to the injury site for RNA isolation. As a control, identical mice were subjected to sham operation and naive nerve tissue was collected.

Sciatic nerve axotomy experiments were performed in adult and newborn rats (the day of birth is considered postnatal day 0 ). In newborn animals, using aseptic technique, the left sciatic nerve was exposed at the sciatic notch and transected with fine scissors. The skin was closed with suture and the pups were resuscitated by warming and then returned to their mothers. The equivalent procedure was performed in adults using standard anesthesia. Pups were killed after 1 or $3 \mathrm{~d}$. Adult rats also were killed after 1 or $3 \mathrm{~d}$. The distal stumps of the axotomized nerves were removed and the most proximal piece $(0.5 \mathrm{~cm})$ collected. Contralateral nerve was collected as a control.

For in vivo LRP-1-antagonism experiments, cohorts of three adult rats were injected directly into the sciatic nerve with $5 \mu$ of GST-RAP $(5 \mu \mathrm{M})$, GST ( $5 \mu \mathrm{M}$ ), or vehicle (20 mm sodium phosphate, $150 \mathrm{~mm} \mathrm{NaCl}, \mathrm{pH} 7.4$, PBS). Nerves were subsequently axotomized immediately above the site of injection. After $24 \mathrm{~h}$, animals were perfused through the ascending aorta with 4\% paraformaldehyde in PBS. Nerve segments distal to the axotomy sites were collected, postfixed in $4 \%$ paraformaldehyde, and processed for paraffin. Sections $(10 \mu \mathrm{m})$ were prepared and analyzed by terminal deoxynucleotidyl transferase (TdT) biotin-dUTP nick-end labeling (TUNEL), using the ApoTag in situ apoptosis detection kit (Chemicon). Slides were counterstained with the nuclear stain, DAPI, and analyzed by immunofluorescence microscopy. In control sections, we omitted TdT and observed no staining.

Primary Schwann cell cultures. Schwann cells were isolated from sciatic nerves of 1-d-old Sprague Dawley rats as described previously (Hiraiwa et al., 1997; Campana et al., 1998) and further selected from fibroblasts using anti-fibronectin antibody and rabbit complement. This resulted in $\sim 99 \%$ pure Schwann cell cultures as assessed by $\$ 100$ immunofluorescence, a specific marker of Schwann cells. Primary Schwann cells were maintained in DMEM containing 10\% fetal bovine serum (FBS), 100 $\mathrm{U} / \mathrm{ml}$ penicillin, $100 \mu \mathrm{g} / \mathrm{ml}$ streptomycin, $21 \mu \mathrm{g} / \mathrm{ml}$ bovine pituitary extract, and $4 \mu \mathrm{M}$ forskolin (complete medium) at $37^{\circ} \mathrm{C}$ under humidified $5.0 \% \mathrm{CO}_{2}$. Schwann cell cultures were passaged no more than three to four times before conducting experiments.

LRP-1 gene silencing. Transfection of Schwann cells in culture with siRNA was optimized by simultaneous introduction of pMAX-green fluorescent protein (GFP) $(2 \mu \mathrm{g})$ and GFP-specific duplex siRNA. Cellular uptake was achieved by electroporation using the Rat Neuron Nucleofector Kit (Amaxa, Gaithersburg, MD). In the absence of siRNA, 55\% of the living cells expressed GFP, as determined by fluorescence microscopy. GFP-specific siRNA ( $25 \mathrm{~nm}$ ) silenced GFP expression in $95 \%$ of the cells. Rat LRP-1-specific siRNAs and pooled nontargeting control (NTC) siRNA were purchased from Dharmacon (Chicago. IL). The LRP-1specific siRNAs included: L1 (sense sequence, GCAUUGGCGUGCAGCUUAAUU); L2 (CGAGCGACCUCCUAUCUUUUU); and L3 (GACCAGUGUUCUCUGAAUAUU). Primary cultures of Schwann cells $\left(1 \times 10^{6}\right)$ were transfected with LRP-1-specific siRNAs (L1-L3; 25 $\mathrm{nM}$ ) or with NTC siRNA (25 nM), using the method determined with GFP-specific siRNA. LRP-1 knock-down was determined by real-time qPCR and by RAP ligand blotting, as described below. 
Cell death studies. Primary Schwann cells and MEFs were plated at 10,000 cells per well in 96-well plates in complete medium. Cells were cultured overnight in complete medium. The cells were then either retained in complete medium, re-equilibrated in DMEM containing $0.5 \%$ FBS, or treated with TNF- $\alpha$ in medium supplemented with $0.5 \%$ FBS for $18 \mathrm{~h}$. Cell death was measured using the cell death ELISA (Roche, Indianapolis, IN), a colorimetric assay that measures the amount of histoneassociated DNA fragmentation (Myers et al., 2003).

TaqMan real-time qPCR. DNA-free total RNA was extracted from frozen nerve tissue and cells in culture using TriZol, as directed by the manufacturer (Invitrogen, Carlsbad, CA). Samples were purified and treated with DNase. cDNA was synthesized using the ProSTAR firststrand reverse transcriptase-PCR kit (Stratagene, San Diego, CA). Expression of target genes, including rat LRP-1, P0, p75 ${ }^{\mathrm{NTR}}$, and mouse LRP-1, was measured by quantitative PCR (qPCR) (MX4000, Stratagene) using a one-step program: $95^{\circ} \mathrm{C}, 10 \mathrm{~min} ; 95^{\circ} \mathrm{C}, 30 \mathrm{~s} ; 60^{\circ} \mathrm{C}, 1 \mathrm{~min}$ for 40 cycles. Cyclophillin or GAPDH gene expression was used as the normalizer for each sample. We and others (MacDonald et al., 2001; Li et al., 2005; Shubayev et al., 2006) have determined previously that both cyclophillin and GAPDH are appropriate and relatively stable housekeeping genes after nerve injury. TaqMan $2 \mathrm{X}$ qPCR master mix was purchased from Applied Biosystems (Foster City, CA). Samples without cDNA were analyzed as "no template" controls. Samples were also studied without previous treatment with reverse transcriptase to confirm the absence of contamination with genomic DNA. Samples were quantified using the comparative Ct method (Livak and Schmittgen, 2001). Threshold cycle $(\mathrm{Ct})$ values (where the increase in fluorescence is exponential) for target genes were normalized to $\mathrm{Ct}$ values for housekeeping genes. The calibrator group (naive or unstimulated cells) was used to determine relative abundance. Data analysis was accomplished using software associated with the Stratagene MX4000, as described previously (Pfaffl, 2001).

Immunoblot analysis and RAP ligand blotting. Protein extracts were prepared from cell cultures or nerve tissue as described previously (Campana et al., 1999; Campana and Myers, 2003). The protein content of each extract was determined by bicinchoninic acid assay (Pierce, Rockville, MD). Equal amounts of cellular protein ( 35 or $50 \mu \mathrm{g}$ ) were subjected to SDS-PAGE and electrotransferred to nitrocellulose membranes. Blots were probed with primary antibodies to detect the light chain of LRP-1 (85 kDa), activated caspase-3, phosphorylated Akt, and total Akt. Antibody binding was detected by HRP-conjugated species-specific secondary antibodies followed by enhanced chemiluminescence (Amersham). In other studies, blots were probed with $0.1 \mu \mathrm{M}$ GST-RAP for $1 \mathrm{~h}$ at $22^{\circ} \mathrm{C}$, to detect RAP-binding members of the LDL receptor family, including LRP-1 and the VLDL receptor, and then with GST-specific antibody.

Immunohistochemistry and microscopy. Heavily anesthetized animals were perfused with fresh $4 \%$ paraformaldehyde containing $0.1 \mathrm{M}$ phosphate buffer. Tissues were removed, post-fixed overnight in perfusate, and processed for paraffin embedding (Campana and Myers, 2001). Paraffin sections were cut $(10 \mu \mathrm{m})$ and incubated with antigen retrieval (Dako, High Wycombe, UK) for $5 \mathrm{~min}$ at $95^{\circ} \mathrm{C}$, and then for $20 \mathrm{~min}$ at room temperature. Nonspecific antibody binding was blocked with $10 \%$ normal mouse serum. Primary antibodies (anti-rat LRP-1 monoclonal antibody or mouse IgG) were incubated overnight at $4^{\circ} \mathrm{C}$ in $0.1 \%$ heattreated horse serum. Slides were rinsed in PBS and subsequently incubated for $1 \mathrm{~h}$ with biotinylated HRP-conjugated anti-mouse or goat antibodies (ABC; Vector Laboratories, Burlingame, CA). Sections were developed with 3'3 diaminobenzidine and counter-stained with methyl green. Some sections were treated only with secondary antibody as a control.

For double-labeling immunofluorescence studies, tissue sections were treated with $0.5 \%$ sodium borohydride in $1 \%$ dibasic sodium phosphate buffer for $5 \mathrm{~min}$, rinsed, and placed in antigen retrieval for $5 \mathrm{~min}$ at $95^{\circ} \mathrm{C}$, as described previously (Myers et al., 2003). Nonspecific binding was blocked with $5 \%$ goat serum for $1 \mathrm{~h}$ at $22^{\circ} \mathrm{C}$. The first primary antibody (polyclonal anti-PGP-9.5; 1:2000) was incubated with the sections for $1 \mathrm{~h}$ at $22^{\circ} \mathrm{C}$. The sections were then rinsed and incubated with goat antirabbit antibody-Alexa 564 conjugate (red) for $1 \mathrm{~h}$ at $22^{\circ} \mathrm{C}$. The second primary antibody, monoclonal antibody $11 \mathrm{H} 4$ (1:20) was then incubated with the sections overnight at $4^{\circ} \mathrm{C}$. Slides were rinsed in PBS containing $0.1 \%$ Tween 20 and subsequently incubated with goat anti-mouse antibody-Alexa 488 conjugate (green) for $1 \mathrm{~h}$ at $22^{\circ} \mathrm{C}$. Finally, the nuclear stain, DAPI (1:20,000), was incubated with each slide for $5 \mathrm{~min}$. Control sections were treated equivalently, but without one primary antibody to assure that immunofluorescence was specific. Imaging was performed using a Leica (Nussloch, Germany) fluorescence microscope and Open Lab software.

Data and statistical analysis. In cell culture experiments, replicates always refer to separate experiments, typically performed with internal duplicates. Animal model experiments were performed using coded animal numbers to avoid observer bias. Data from qPCR studies, immunoblots, in situ TUNEL assays, and cell death assays were subjected to ANOVA. Tukey's or Kramers-Neuman-Keuls post hoc analysis was used to assess the differences between treatment groups. In some cases, data from siRNA studies or knock-out mice studies were analyzed by a $t$ test.

\section{Results}

\section{LRP-1 expression in injured sciatic nerve}

To determine whether LRP-1 is expressed in adult sciatic nerve and the cell types that may be involved, we initially performed immunohistochemistry experiments. We used monoclonal antibody $11 \mathrm{H} 4$, which recognizes the $85 \mathrm{kDa}$ LRP-1 light-chain (Wu and Gonias, 2005). In control experiments, we demonstrated intense $11 \mathrm{H} 4$ immunopositivity in rat liver, where LRP-1 is known to be abundant (Ling et al., 2004), and no staining in heart, which is known to be LRP-1-negative (Moestrup et al., 1992) (data not shown). Figure $1 A$ shows that in naive, uninjured sciatic nerve, LRP-1 immunoreactivity was most intense in the axoplasm. LRP-1 was also detected, but to a much lesser extent, in association with myelinating Schwann cells (solid arrows point to Schwann cell crescents).

Adult rats were subjected to sciatic nerve crush injury. LRP-1 expression in the distal segment, adjacent to the crush injury, was examined 1 and $3 \mathrm{~d}$ later. At both time points, Schwann cell crescents (arrows and insets) showed substantially increased LRP-1 immunopositivity (Figs. $1 B, C$ ). In the same time period, LRP-1 immunopositivity became less abundant in deteriorating axoplasm. Figure $1 \mathrm{D}$ shows that immunoreactivity was not detected when the primary antibody (11H4) was omitted. In an additional control experiment, we demonstrated that LRP-1 immunohistochemistry was not changed by crush injury in contralateral nerves (data not shown).

To confirm that LRP-1 immunopositivity localizes to Schwann cells after sciatic nerve crush injury, we performed double-labeling immunofluorescence microscopy studies. Sections from injured nerve were immunostained to detect axoplasm (red), using PGP-9.5-specific antibody, and to detect LRP-1 (green), using antibody $11 \mathrm{H} 4$. Figure $1 E$ shows representative images of Schwann cells in association with axoplasm. LRP-1 was detected primarily in cytoplasmic crescents surrounding PGP-9.5-positive areas. The irregular shapes of the PGP-9.5staining areas suggest axoplasm deterioration. Overlaying of the fluorescent images demonstrated that trace levels of LRP-1 may have been associated with the PGP-9.5-positive axoplasm; however, the majority of the LRP-1 did not colocalize. These results support the hypothesis that in injured sciatic nerve, LRP-1 is expressed primarily by Schwann cells and to a lesser extent by axons. Although macrophages, which infiltrate injured nerve, may express LRP-1 (Moestrup et al., 1992), macrophages are not prevalent in the endoneurium until more than $3 \mathrm{~d}$ after injury (Stoll et al., 2002).

Next, we performed immunoblot analysis using antibody 
$11 \mathrm{H} 4$ to detect LRP-1 in extracts of naive sciatic nerve and distal nerve segments after crush injury. Immunoblot analysis provides a semiquantitative method for determining the total level of LRP-1 in a tissue, without distinguishing the cellular source. As shown in Figure $1 F$, LRP-1 was readily detected before and after injury. Densitometry analysis of the LRP-1 bands, standardized against $\beta$-actin, showed that the total level of LRP-1 was decreased by $42 \pm$ $4 \%$ at day 3 , as might be predicted by the immunohistochemistry; however, the residual LRP-1 after nerve injury suggested that the increase in Schwann cell LRP-1 partially offsets the decrease observed in axoplasm.

Schwann cells comprise $90 \%$ of the nucleated cells in the uninjured endoneurium (Asbury and Johnson, 1978). Because of the low level of mRNA in axoplasm, Schwann cells are responsible for the majority of the mRNA recovered from the peripheral nerve. To confirm our hypothesis that LRP-1 is upregulated in Schwann cells in vivo after peripheral nerve injury, we examined LRP- 1 mRNA by qPCR. Rat LRP-1 TaqMan probes and primers were designed. These probes and primers amplified a single band with the anticipated size (68 bp) in adult rat nerve (Fig. $2 \mathrm{~A}$, lane 1). The identical band was observed when we amplified cDNA from rat liver (data not shown), a known source of abundant LRP-1 (Ling et al., 2004). In the absence of template, there were no bands and no evidence of primer dimers (lane 3 ).

When adult rat sciatic nerve was subjected to crush injury, LRP-1 mRNA increased more than fourfold in the distal nerve stump within $1 \mathrm{~d}(p<0.01)$ (Fig. $2 B)$. The amount of LRP-1 mRNA subsequently decreased; however, the level remained significantly elevated compared with that present in the uninjured (naive) nerve for at least $7 \mathrm{~d}(p<0.05)$. In these experiments, rat cyclophillin was used to normalize LRP-1 mRNA levels and naive nerve was used as a calibrator to determine relative abundance. LRP-1 mRNA was not regulated in L5 DRG (Fig. 2C), suggesting that LRP-1 is specifically regulated at the injury site. LRP-1 mRNA also was not regulated in the contralateral nerve (data not shown). The increase in LRP-1 mRNA distal to the site of peripheral nerve injury supports our model in which LRP-1 is selectively upregulated in Schwann cells.

\section{TNF- $\alpha$ regulates LRP-1 expression in chronic constriction injury}

To further test the effects of peripheral nerve injury on LRP-1 expression, we used a second nerve injury model system, CCI.

E
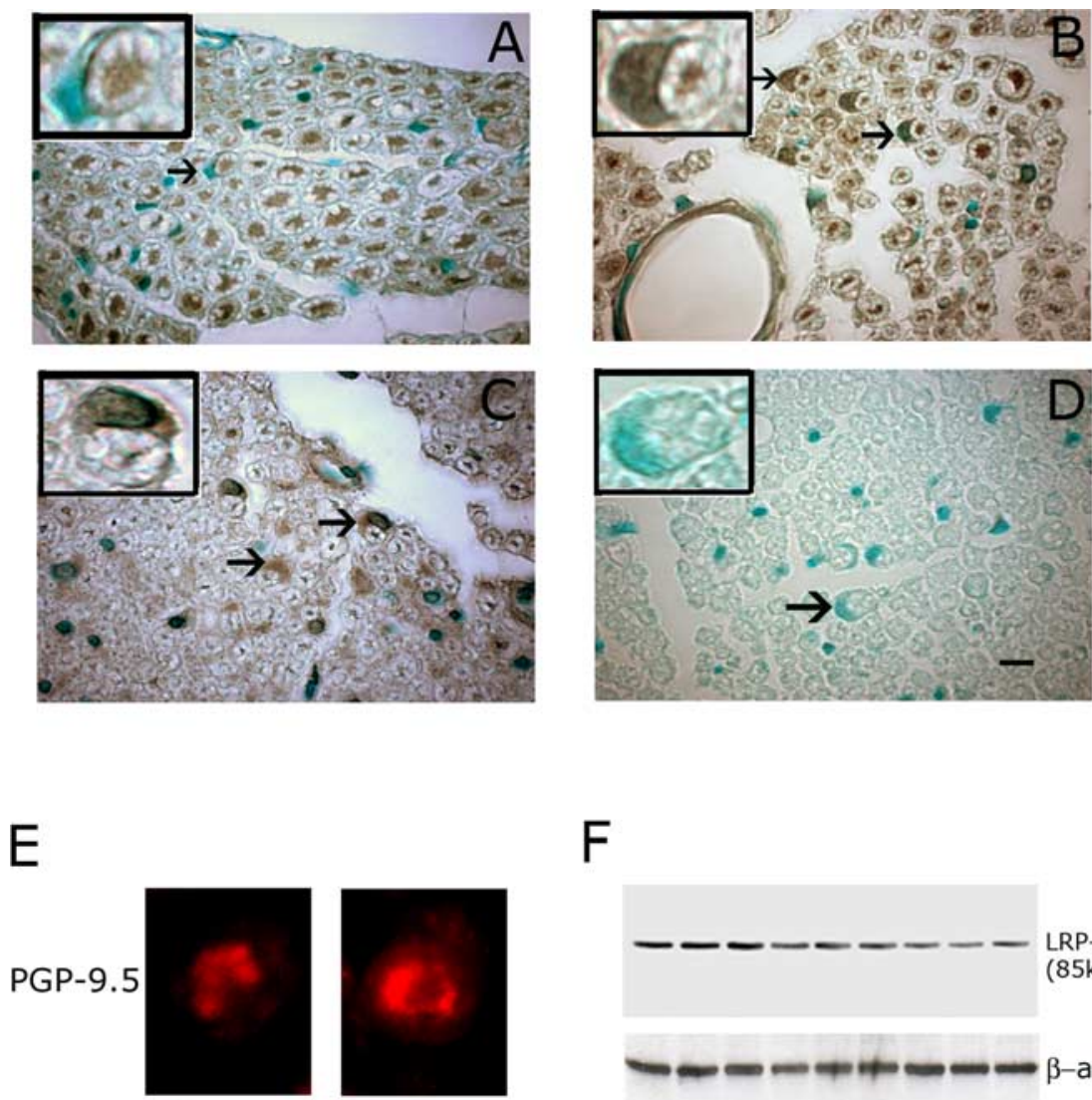

F
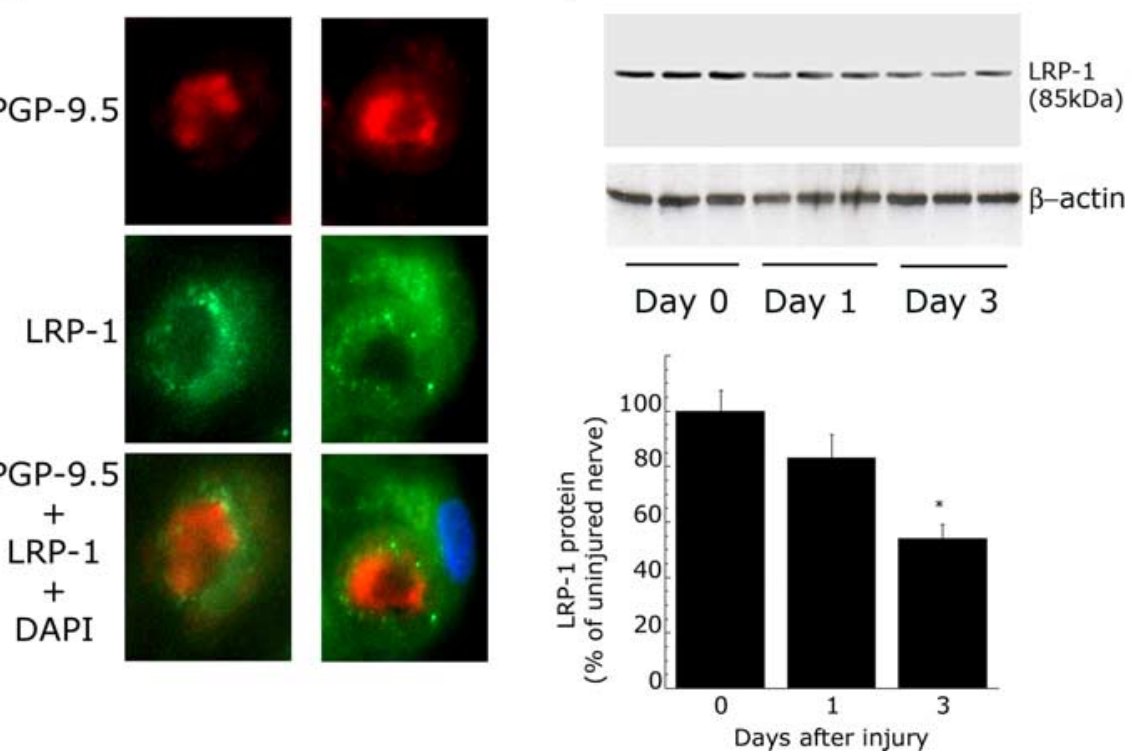

Figure 1. LRP-1 immunohistochemistry and protein levels in adult rat sciatic nerve. LRP-1 protein expression was studied by immunohistochemistry using antibody $11 \mathrm{H} 4$, which recognizes the LRP-1 $85 \mathrm{kDa}$ light chain. $\boldsymbol{A}$, Uninjured nerve. $\boldsymbol{B}, \boldsymbol{C}$, Sciatic nerve that was subjected to crush injury is shown $1 \mathrm{~d}(\boldsymbol{B})$ and $3 \mathrm{~d}$ after injury $(\boldsymbol{C})$. $\boldsymbol{D}$, This photomicrograph shows injured nerve in which primary antibody was omitted. Photomicrographs were prepared at $1000 \times$ magnification and are representative of $n=$ 4/group. Scale bar, $45 \mu \mathrm{m}$. Insets are magnified images of myelinated axons with surrounding Schwann cell cytoplasm. The black arrows demarcate Schwann cell cytoplasm that is increasingly immunopositive for LRP-1 after injury. $\boldsymbol{E}$, Double-labeling immunofluorescence for LRP-1 (green) and PGP-9.5 (red). Nuclei are marked with DAPI (blue). The two representative fields show distal nerve $3 \mathrm{~d}$ after crush injury. Photomicrographs were prepared at $1000 \times$ magnification and are representative of $n=6 /$ group. Merged images are shown at the bottom. $\boldsymbol{F}$, LRP-1 protein in nerve extracts was determined by immunoblot analysis using antibody 11H4. SDS-PAGE was conducted using $35 \mu \mathrm{g}$ of protein extract from uninjured nerve (day 0 ) and from injured nerve, 1 and $3 \mathrm{~d}$ after crush injury. The same extracts were probed for $\beta$-actin. Densitometric analysis of the ratio of LRP-1 to $\beta$-actin in naive and injured nerve is also shown ( $n=3$ /group). ${ }^{*} p<0.05$.

This model differs from crush injury in that the axons are less uniformly damaged. Therefore, axonal degeneration and regeneration occurs without the same degree of synchrony, as is described in crush injury. CCI has a greater inflammatory component than crush injury and ischemia contributes to the pathology observed (Bennett and Xie, 1988; Myers et al., 1993; Campana et al., 2006). Our experiments were performed in mice instead of 

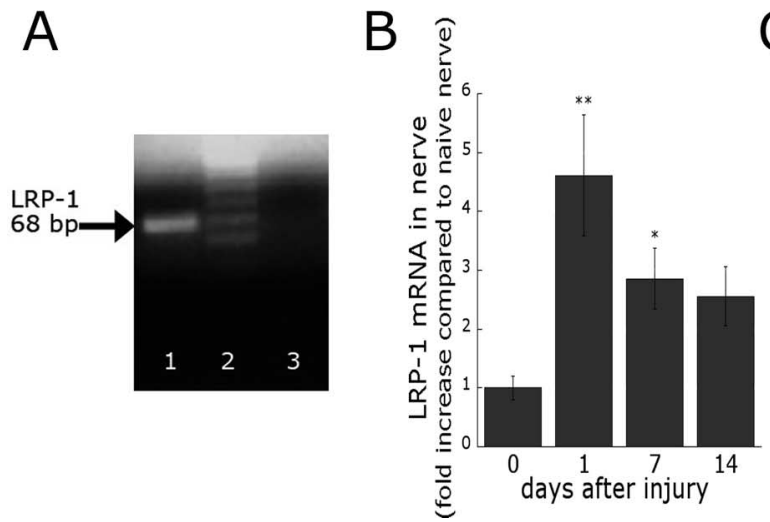

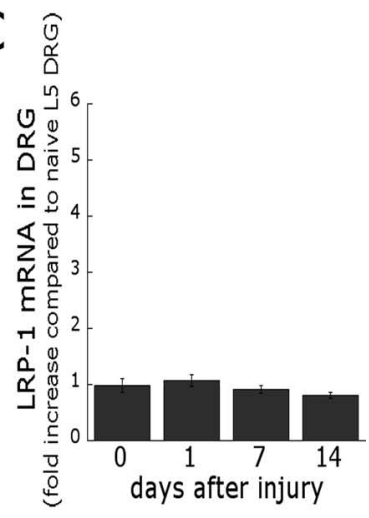

Figure 2. LRP-1 mRNA is increased in adult rat distal sciatic nerve after crush injury. $A$, cDNA prepared from adult nerve ( $1 \mu \mathrm{g})$ was amplified by qPCR and subjected to $4 \%$ agarose gel electrophoresis in lane 1 . The LRP- 1 primers amplified a band with the anticipated 68 bp size. Lane 2 shows a $25 \mathrm{~kb}$ DNA ladder (100 ng). Lane 3 shows the "no template" control. Ethidium bromide was used to detect DNA. $\boldsymbol{B}, \mathrm{LRP}-1 \mathrm{mRNA}$ levels in the sciatic nerve, distal to the crush injury site, were determined by $q \mathrm{PCR}, 1,7$, and $14 \mathrm{~d}$ after injury. Results are compared with naive (uninjured) sciatic nerve. C, LRP-1 mRNA in the L5 DRG, ipsilateral to the injury site, was determined by $q P C R$ and standardized against LRP- 1 in naive L5 DRG. The results were analyzed by one-way ANOVA comparing each day to the uninjured tissue (day 0$) .{ }^{*} p<0.05 ;{ }^{* *} p<0.01$ ( $n=5 /$ group). Error bars indicate SEM. creased; however, the increase was delayed and significantly decreased in magnitude. No significant change in LRP-1 mRNA was observed in the contralateral nerve in wild-type or TNF- $\alpha-/-$ mice. When TNF- $\alpha$ was injected directly into the CCI site $(2 \mu \mathrm{l}, 100 \mathrm{ng}$ of solution) in TNF$\alpha-/-$ mice, LRP-1 was increased ninefold within $1 \mathrm{~d}$, demonstrating rescue of the response. The TNF- $\alpha$ vehicle $(0.1 \%$ bovine serum albumin in PBS) did not significantly affect LRP-1 mRNA expression in either $T N F-\alpha-/-$ or wild-type mice. These results and the results of our crush injury experiments demonstrate that LRP-1 is increased in two separate models of peripheral nerve injury, in mice and in rats. The increase appears to be mediated primarily by TNF- $\alpha$; however, when TNF- $\alpha$ is deficient, other mediators also may increase LRP-1 expression in a delayed manner.

To further explore the activity of
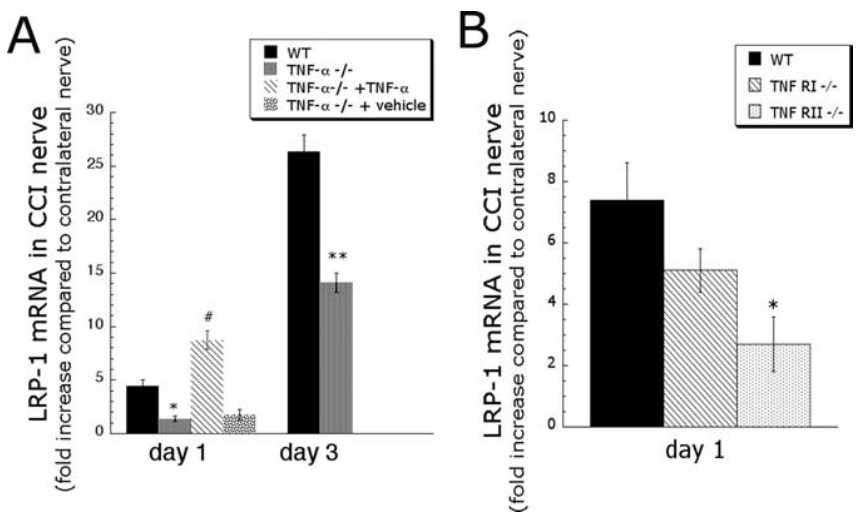

Figure 3. Regulation of LRP-1 mRNA expression in injured nerves in TNF- $\alpha-/-$ mice, TNFRI-I- mice, and TNFRII-I- mice. A, TNF- $\alpha-/-$ and wild-type (WT) mice were subjected to $\mathrm{CCl}$. In some animals, TNF- $\alpha(100 \mathrm{ng})$ or vehicle was injected directly into the $\mathrm{CCl}$ site. LRP-1 mRNA was determined by qPCR 1 or $3 \mathrm{~d}$ post-CCI ( $n=3-5 /$ group). Statistical analysis ( $t$ test) was performed comparing LRP-1 mRNA in wild-type and TNF- $\alpha-1-$ mice on the same day (mean $\pm \mathrm{SEM} ;{ }^{*} p<0.05 ;{ }^{* *} p<0.01 ;{ }^{*}$ comparison between TNF- $\alpha$ and vehicle injected TNF- $\alpha-/-$ mice). $B$, CCI was induced in TNFRI $-/-$, TNFRII-I-, and in WT mice of the same genetic background. mRNA levels were determined by $q$ PCR using GAPDH as a normalizer. WT, $n=9 ;$ TNFRI $-/-$ and TNFRII $-/-, n=4-5$. All results are expressed as the fold increase compared with uninjured, contralateral nerve (mean \pm SEM; ${ }^{*} p<0.05$ ).

rats, allowing us to test whether TNF- $\alpha$ regulates LRP-1 expression by comparing wild-type and TNF- $\alpha$ gene knock-out mice. It has been suggested that TNF- $\alpha$ orchestrates many of the changes in cell physiology observed in the injured peripheral nerve (Wagner and Myers, 1996; Shamash et al., 2002; Campana et al., 2006).

Wild-type and TNF- $\alpha$ gene knock-out mice, in the same genetic background (B6;129SF2/J), were subjected to CCI. Mouse LRP-1 mRNA was measured distal to the injury site. GAPDH was also measured, as a normalizing control. Uninjured (naive) mouse nerve was used as a calibrator to determine relative mRNA abundance. Figure $3 A$ demonstrates that LRP-1 mRNA increased significantly, by approximately fourfold and 25-fold on days 1 and 3, respectively, after initiation of CCI injury in wild-type mice. In the TNF- $\alpha-/-$ mice, LRP-1 mRNA levels also in-
TNF- $\alpha$ in regulating LRP-1 expression, we executed CCI experiments in TNFRI-/ - and TNFRII-/- mice. As a control, we examined wild-type mice in the same genetic background. Figure $3 B$ shows that the increase in LRP- 1 mRNA $1 \mathrm{~d}$ after initiating $\mathrm{CCI}$ in wild-type mice in the C57BL/6J genetic background was approximately eightfold, which is somewhat greater than that observed in the B6;129SF2/J genetic background (Fig. 3, compare $A, B)$. The increase in LRP-1 mRNA was significantly dampened in the TNFRII-/- mouse. A smaller change in LRP-1 mRNA expression was observed in the TNFRI-/- mouse, which was not statistically significant.

\section{LRP-1 expression in developing nerve}

Peripheral nerves become myelinated during the first $1-2$ weeks after birth. This is accompanied by expression of P0, a marker of the myelinated phenotype. Neonatal Schwann cells lack established autocrine circuits and, thus, are susceptible to cell death after denervation (Jessen and Mirsky, 2005). Figure $4 A$ shows that LRP-1 mRNA increased significantly over the first $7 \mathrm{~d}$ after birth, at the same time that P0 mRNA increased. Thus, LRP-1 expression may increase with maturation of Schwann cells.

Because it is difficult to execute other forms of sciatic nerve injury in newborn rats, the pups were subjected to axotomy. LRP-1 mRNA was measured in $1 \mathrm{~mm}$ nerve segments immediately adjacent to the distal side of axotomy. As shown in Figure $4 B$, LRP-1 mRNA failed to increase 1 or $3 \mathrm{~d}$ after injury. As a positive control, we showed that $\mathrm{p} 75^{\mathrm{NTR}}$ mRNA was substantially increased in the same tissue specimens, as anticipated (Grinspan et al., 1996; Syroid et al., 2000).

Our axotomy results with rat pups suggested that Schwann cell LRP-1 expression may increase in response to injury exclusively in adult animals and not in newborns that have incompletely differentiated Schwann cells. To confirm that the absence of LRP-1 regulation was caused by the age of the animals and not the model system applied (axotomy vs crush injury or CCI), we performed axotomy experiments in adult rats. Figure $4 C$ shows that LRP-1 was significantly increased $3 \mathrm{~d}$ after axotomy in the distal stump of adult nerves. p75 ${ }^{\text {NTR }}$ mRNA also was increased in the same nerve specimens (Fig. 4D). 


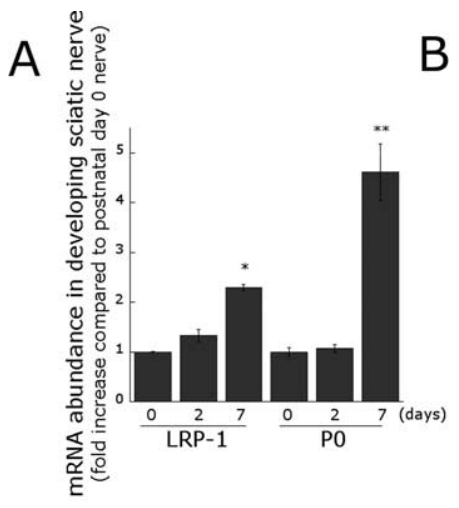

C

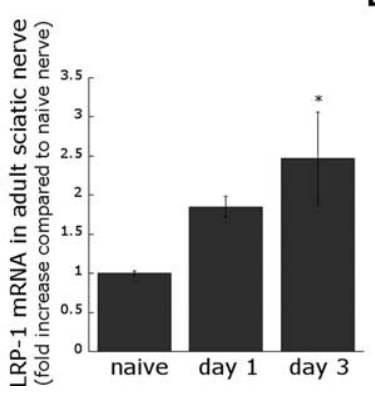

$\mathrm{D}$

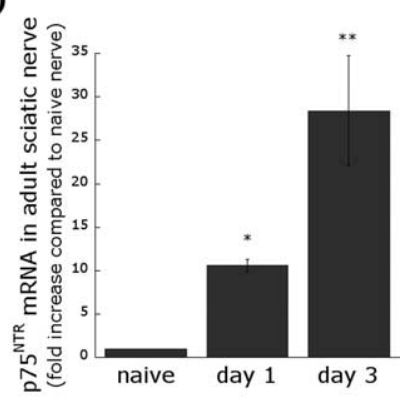

Figure 4. LRP-1 mRNA increases in adult distal nerve after axotomy, but not after neonatal axotomy. $\boldsymbol{A}, \mathrm{LRP}-1$ and PO mRNA were determined in developing sciatic nerve by qPCR at the indicated number of days after birth. $\boldsymbol{B}$, Newborn rat pups (postnatal day 0 ) were subjected to sciatic nerve axotomy. LRP-1 and p75 ${ }^{\text {NTR }}$ mRNA levels were determined in the injured distal nerve 1 and $3 \mathrm{~d}$ after axotomy. $C$, Adult rats were subjected to sciatic nerve axotomy. LRP-1 mRNA was determined in the distal segment 1 and $3 \mathrm{~d}$ after axotomy and compared with the level in uninjured nerve (naive). D, p75 ${ }^{\mathrm{NTR}}$ mRNA was determined in the distal segments of axotomized adult sciatic nerves. All results ( $n=4-5 /$ group) were expressed as mean \pm SEM and were analyzed by ANOVA. *Significant difference $(p<0.05)$ between the marked bar and either day $0(\boldsymbol{A})$ or uninjured nerve $(\boldsymbol{C}, \boldsymbol{D}) .{ }^{* *}$ Significance at the $p<0.01$ level.

\section{Schwann cell LRP-1 protects against cell death in vitro}

To further study regulation of LRP-1 expression and the activity of LRP-1 in Schwann cells, we established rat Schwann cell primary cultures. Previous studies indicate that primary cultures represent an appropriate model of Schwann cell physiology in the denervated distal stump of injured nerves (Jessen et al., 1990). Early passage $(<5)$ Schwann cells in culture were treated with various concentrations of TNF- $\alpha$ for $6 \mathrm{~h}$. LRP-1 mRNA was measured by qPCR. Although LRP-1 mRNA was readily detected in Schwann cells maintained in complete medium, transfer to $0.5 \%$ FBS and treatment with TNF- $\alpha$ significantly increased LRP-1 mRNA expression (Fig. 5). At TNF- $\alpha$ concentrations of $25 \mathrm{ng} / \mathrm{ml}$ or higher, the increase in LRP-1 mRNA was $>50$-fold $(p<0.01)$.

To study the function of LRP-1 in Schwann cells in primary culture, we applied a gene-silencing approach. Schwann cells were transfected with a battery of candidate rat LRP-1-specific siRNAs or with NTC siRNA. As shown in Figure 6A, siRNA L1 decreased LRP-1 mRNA by $95 \%$ within $24-48$ h. siRNA L 2 and L3 decreased LRP-1 mRNA by $\sim 90 \%$. No change in LRP-1 mRNA was observed in cells that were transfected with NTC siRNA.

To confirm that LRP-1-silencing was achieved at the protein level as well as at the mRNA level, we studied cultures transfected with siRNA L1 or with NTC siRNA by RAP ligand blotting. This method detects LRP-1 and other members of the LDL receptor

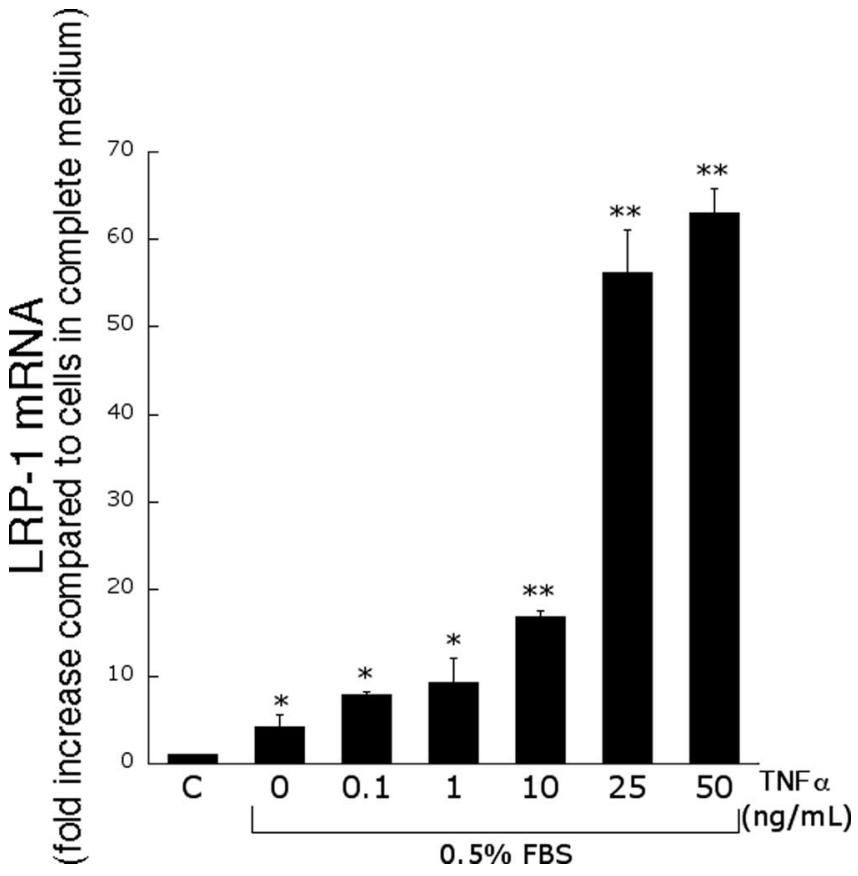

Figure 5. TNF- $\alpha$ increases LRP-1 mRNA expression by Schwann cells in primary culture. Schwann cells were treated with increasing concentrations of TNF- $\alpha(0-50 \mathrm{ng} / \mathrm{ml})$ in medium supplemented with $0.5 \%$ FBS. LRP- 1 mRNA was analyzed by qPCR ( $n=5 /$ treatment). Results are expressed as the fold increase relative to cells that were maintained in $10 \%$ FBSsupplemented medium without TNF- $\alpha$ (C). Results were analyzed by ANOVA with Tukey's post hoc test. ${ }^{*} p<0.05 ;{ }^{* *} p<0.01$.

gene family (Williams et al., 1992; Medh et al., 1995). Figure $6 B$ shows that a major band at $\sim 500 \mathrm{kDa}$, consistent with the known mass of the LRP-1 heavy chain, was silenced by siRNA L1. The same band was unaffected by NTC siRNA. A second faint band with an apparent mass of $110 \mathrm{kDa}$ was also detected, consistent with the known mass of the VLDL receptor (Strickland et al., 2002). This band was not significantly affected by siRNA L1 or NTC siRNA. As an additional control for load, we demonstrated equivalent levels of $\beta$-actin in the cell extracts that were probed by RAP ligand blotting.

Schwann cells in which LRP-1 was silenced, with either siRNA L1 or siRNA L2, and cells that were transfected with NTC siRNA, were cultured in $0.5 \%$ FBS-containing medium, with or without TNF- $\alpha$. The incubations were initiated $24 \mathrm{~h}$ after introducing siRNA and allowed to progress for $18 \mathrm{~h}$. Cell death was determined by the cell death ELISA, which detects intracytoplasmic oligonucleosomes. The extent of cell death was compared with that observed in untransfected cultures that were maintained in $10 \%$ FBS-supplemented (complete) medium. Cell death was not affected by the siRNAs when the cultures were maintained in complete medium (data not shown); however, when the cultures were transferred to medium that contained $0.5 \%$ FBS, a significant increase in cell death was observed (Fig. 6C). Cell death was increased further by TNF- $\alpha$. The increase in cell death caused by serum deprivation or TNF- $\alpha$ was comparable for untransfected cells and cells transfected with NTC siRNA. In contrast, Schwann cells in which LRP-1 was silenced with either siRNA-L1 or siRNA-L2 demonstrated significantly increased cell death both in $0.5 \%$ FBS and after treatment with TNF- $\alpha$. These results demonstrate that LRP-1 protects Schwann cells in culture from cell death induced by serum deprivation or by TNF- $\alpha$. 


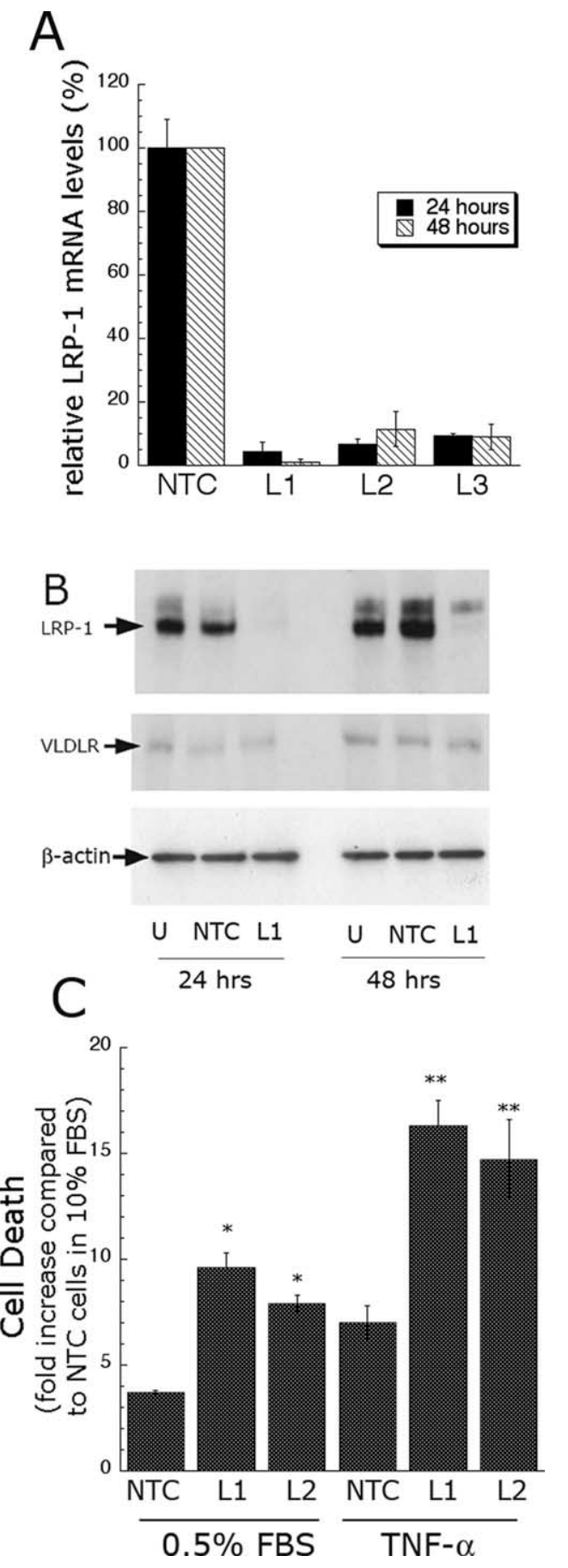

Figure 6. Schwann cells in primary culture that are deficient in LRP-1 have increased susceptibility to cell death in response to serum deprivation or TNF- $\alpha$. A, Schwann cells in culture were transfected with pooled nontargeting control siRNA (NTC) or with three separate LRP-1specific siRNAs (L1, L2, L3). LRP-1 mRNA was determined by qPCR, 24 and $48 \mathrm{~h}$ after transfection. The level of LRP-1 mRNA in cells transfected with NTC siRNA was not significantly changed compared with untransfected cells. $\boldsymbol{B}$, LDL receptor family members were detected by RAP ligand blotting in Schwann cells that were untransfected (U), transfected with NTC siRNA (NTC), or transfected with LRP-1-specific siRNA L1. Equal amounts of cell extract (35 $\mu \mathrm{g}$ of protein) were loaded in each lane. The same blots were probed for $\beta$-actin by immunoblot analysis as a loading control. C, Schwann cells in which LRP-1 was silenced with L1 or L2 and cells that were transfected with NTC siRNA were exposed to medium supplemented with $0.5 \%$ FBS, with or without TNF- $\alpha$, for $18 \mathrm{~h}$. Cell death was monitored by the cell death ELISA. Data $(n=4)$ are expressed as mean \pm SEM. Cells in which LRP-1 was silenced with L1 or L2 and exposed to $0.5 \%$ FBS or TNF- $\alpha$ demonstrated significantly increased cell death $\left({ }^{*} p<0.05\right.$ or ${ }^{* *} p<0.01$, respectively) compared with cells that were transfected with NTC siRNA and exposed to $0.5 \%$ FBS or TNF- $\alpha$.

\section{A}

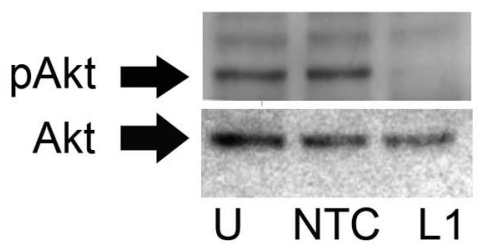

B

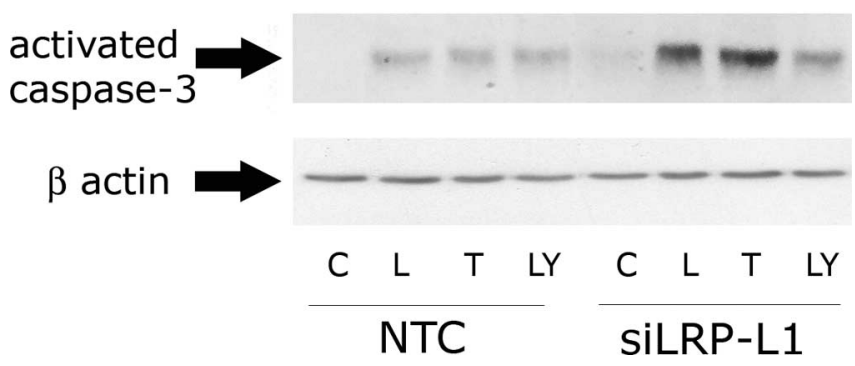

Figure 7. Activation of proapoptotic signaling in Schwann cells deficient in LRP-1. A, Schwann cells that were untransfected $(U)$, transfected with pooled nontargeting control siRNA (NTC), or transfected with LRP-1 specific siRNA L1 (L1) were transferred into 0.5\% FBSsupplemented medium for $18 \mathrm{~h}$. pAkt and total Akt were determined by immunoblot analysis ( $n=4 /$ group). B, Schwann cells were maintained in 10\% FBS-supplemented medium (C), transferred to $0.5 \%$ FBS-supplemented medium (L), treated with TNF- $\alpha(50 \mathrm{ng} / \mathrm{ml})$ in $0.5 \%$ FBS (T), or treated with $20 \mu \mathrm{m}$ LY294002 in 10\% FBS (LY) for $3 \mathrm{~h}$. Activated caspase-3 was detected by immunoblot analysis ( $n=3$ /group). In the bottom, we probed for $\beta$-actin as a loading control.

LRP-1-dependent pro-survival cell signaling in Schwann cells The PI3K-Akt pathway activates pro-survival signaling proteins in the cell (Brunet et al., 2001; Anitha et al., 2006). Previous studies indicate that receptors in the LDL receptor family may activate PI3K (Bock et al., 2003). To determine whether LRP-1 regulates the PI3K-Akt pathway in Schwann cells, we determined phosphorylated Akt (pAkt) and total Akt in cultured Schwann cells in which LRP-1 was silenced with siRNA-L1. Control cells were transfected with pooled NTC siRNA or not transfected. All three cell populations were cultured in $0.5 \%$ FBS-containing medium for $18 \mathrm{~h}$. Cell extracts were prepared and Akt phosphorylation was determined by immunoblot analysis. As shown in Figure $7 A$, pAkt was equivalent in the untransfected cells (U) and in the cells that were transfected with pooled NTC siRNA. In contrast, Schwann cells, in which LRP-1 was silenced, demonstrated almost undetectable levels of phosphorylated Akt.

To further test our hypothesis that LRP-1 functions as a prosurvival receptor in Schwann cells, we determined levels of activated caspase-3 in Schwann cells that were transfected with siRNA-L1 or with NTC siRNA (Fig. 7B). Caspase-3 is an executioner caspase that functions downstream of the intrinsic and extrinsic death pathways (Thorburn, 2004). Cells were maintained in $10 \%$ FBS (C), exposed to $0.5 \%$ FBS (L), treated with TNF- $\alpha(\mathrm{T})$, or treated with the pharmacological PI3K inhibitor, LY294002 (LY), in 10\% FBS for 3 h. Activated caspase-3 was determined by immunoblot analysis, using an antibody that detects only the cleaved, activated form. Under all three treatment conditions, activated caspase- 3 was increased in LRP-1-silenced cells. The increase in activated caspase- 3 was least pronounced with LY294002, which was anticipated because the level of activated PI3K is already decreased in LRP-1-silenced cells. 
A

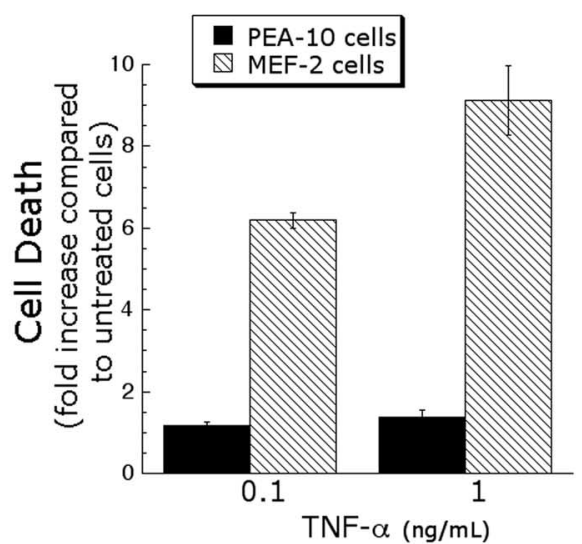

B
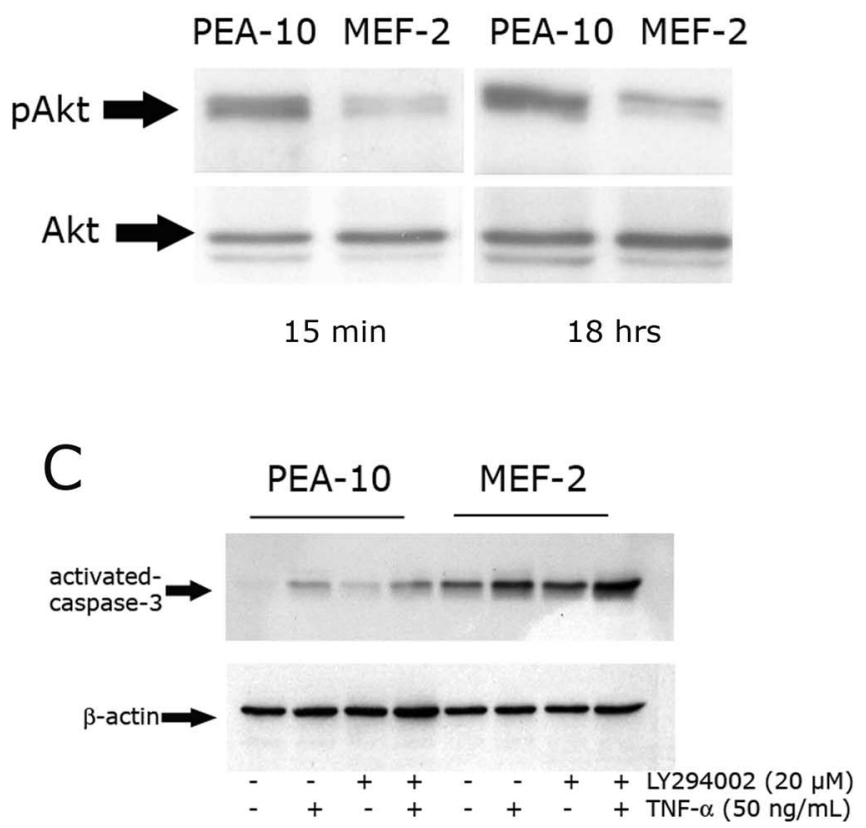

Figure 8. LRP-1-deficient MEFs are more susceptible to TNF- $\alpha$-mediated cell death. $\boldsymbol{A}, \mathrm{LRP}$ 1-expressing PEA-10 cells and LRP-1-deficient MEF-2 cells were treated with the indicated concentrations of TNF- $\alpha$ for $18 \mathrm{~h}$. Cell death was measured by the cell death ELISA. Results are expressed as the mean \pm SEM ( $n=4 /$ group). $B$, PEA-10 cells and MEF- 2 cells were cultured in $0.5 \%$ FBS-supplemented medium for $15 \mathrm{~min}$ or $18 \mathrm{~h}$. pAkt and total Akt (Akt) was determined by immunoblot analysis. C, PEA-10 cells and MEF-2 cells were cultured for $18 \mathrm{~h}$ in $0.5 \%$ FBSsupplemented medium with TNF- $\alpha$ and/or the PI3K inhibitor LY294002 as indicated in the figure. Activated caspase- 3 was determined by immunoblot analysis $(n=4)$.

To verify our results regarding the function of LRP-1 as a pro-survival receptor in a model of complete LRP-1 deficiency, we compared MEFs that are genetically deficient in LRP-1 (MEF-2 cells) with LRP-1-positive MEFs (PEA-10 cells). These clones were selected from the same original culture (Willnow and Herz, 1994). Both cell types were exposed to low concentrations of TNF- $\alpha(0.1-1.0 \mathrm{ng} / \mathrm{ml})$ in $0.5 \%$ FBS-containing medium. Cell death was determined by the cell death ELISA. As shown in Figure $8 A$, the low concentrations of TNF- $\alpha$ failed to induce PEA-10 cell death; however, substantial MEF-2 cell death was observed. When the TNF- $\alpha$ concentration was increased to $50 \mathrm{ng} / \mathrm{ml}$, PEA-10 cell death was observed as well, as anticipated (data not shown).

Next, we examined Akt phosphorylation and caspase- 3 activation in the LRP-1-expressing and -deficient MEFs. PEA-10 and MEF-2 cells were cultured for $15 \mathrm{~min}$ or $18 \mathrm{~h}$ in $0.5 \%$ FBS- containing medium. As shown in Figure $8 B$, phosphorylated Akt was substantially higher in the LRP-1-expressing MEFs at both time points. Figure $8 C$ shows that activated caspase- 3 was increased in the LRP-1-deficient MEF-2 cells, compared with PEA-10 cells, when the cultures were maintained in $0.5 \%$ FBScontaining medium, treated with TNF- $\alpha$, treated with LY294002, or treated with TNF- $\alpha$ in combination with LY294002. Thus, absolute LRP-1 deficiency in MEFs generates the equivalent perturbations in cell signaling that are observed in Schwann cells, in which LRP-1 is silenced with siRNA.

\section{Antagonizing LRP-1 with the competitive inhibitor RAP increases apoptosis in distal stumps of axotomized nerves} To test whether LRP-1 functions as a Schwann cell pro-survival receptor in vivo, we injected GST-RAP or, as a control, GST ( $5 \mu \mathrm{l}$ of $0.8 \mu \mathrm{M}$ solution) directly into sciatic nerves that were then immediately axotomized. An equivalent volume of vehicle (PBS) was injected as a second control. GST-RAP is an LRP-1 antagonist that binds to the LRP-1 heavy chain and blocks the binding of all other known ligands, including $\alpha 2$-macroglobulin, tissuetype plasminogen activator, and urokinase-type-plasminogen activator-PAI-1 complex, which have been reported to regulate LRP-1-dependent cell signaling (Bacskai et al., 2000; Webb et al., 2001; Hu et al., 2006). Death of nucleated cells within the nerve was examined by TUNEL, $24 \mathrm{~h}$ after axotomy, when Schwann cells constitute $>90 \%$ of the nucleated cells. DAPI staining was performed to mark nuclei.

Figure $9 A$ shows that a significant fraction of the DAPIstained nuclei also stained positively for TUNEL in the GSTRAP-treated nerves. A lower level of TUNEL-positivity was observed in the GST-treated nerves. The results are summarized in Figure 9B. Almost no TUNEL positivity was observed in vehicletreated nerves. GST induced occasional TUNEL-positive cells. In contrast, GST-RAP induced a significant increase in cell death, compared with that observed in vehicle-treated or GST-treated nerves; $\sim 20 \pm 5 \%$ of the nucleated cells detected with DAPI were also TUNEL-positive. As a control, we compared the total number of DAPI-positive nuclei in all of the fields reviewed for TUNEL positivity. The average number of DAPI-stained nuclei/ field was not significantly different in the various treatment groups (data not shown).

Because RAP antagonizes LDL receptor family members other than LRP-1, we isolated protein extracts from uninjured sciatic nerve and subjected these to RAP ligand blotting. Figure $9 C$ shows that a single major band with an apparent mass approximating that of the LRP-1 heavy chain was detected. Other RAPbinding candidates, $(>100 \mathrm{kDa})$ such as VLDL receptor, were not observed. Although we cannot fully rule out the possibility that RAP induced cell death in axotomized nerve included inhibiting an LDL receptor family member, that was either present in lowabundance or undetected by our RAP ligand-binding experiments, these in vivo studies and our in vitro experiments strongly support a model in which LRP-1 functions as a Schwann cell survival receptor.

\section{Discussion}

Survival of adult Schwann cells depends on autocrine signaling circuits, involving factors such as PDGF, neurotrophin-3, and IGF-II (Meier et al., 1999). Because LRP-1 is a multifunctional receptor (Strickland et al., 2002; Gonias et al., 2004), binding numerous ligands generated at injury sites and controlling diverse cell-signaling pathways, we initiated experiments to determine whether LRP-1 regulates the response to peripheral nerve injury. In the uninjured nerve, LRP-1 was abundant. After crush 
A

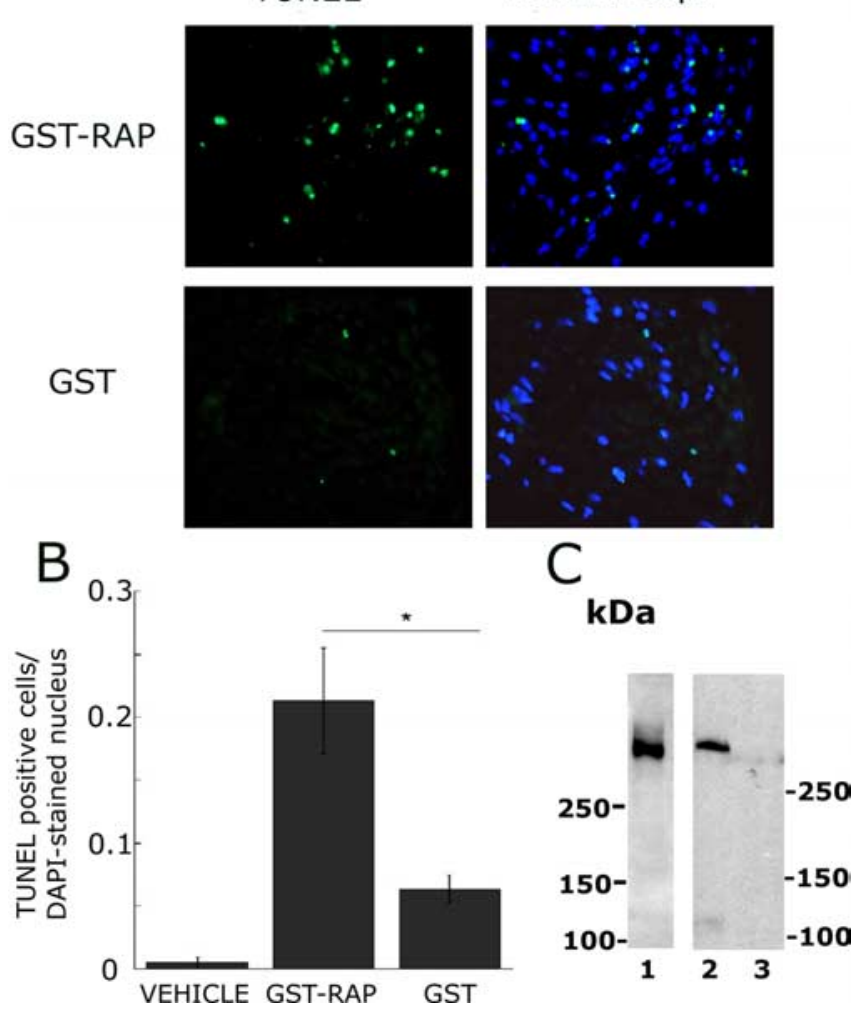

Figure 9. Antagonizing LRP-1 with RAP induces cell death in adult nerve after axotomy in vivo. A, GST-RAP or GST was injected into rat sciatic nerves. Axotomies were then performed immediately proximal to the injection site. Nerves were harvested $24 \mathrm{~h}$ later. Cell death was detected in representative sections by immunofluorescence microscopy as TUNEL-positive (green) endoneural cells. Nucleated cells are marked with DAPI (blue). The photomicrographs are representative of two sections examined for each of three animals per group. $\boldsymbol{B}$, Quantification of TUNEL-positive cells after injection of vehicle (PBS), GST-RAP, or GST into axotomized nerves. The number of TUNEL-positive cells per DAPI-positive nucleus is plotted. Three representative fields from two sections of nerve from each animal ( $n=3 /$ group) were examined to generate this bar graph. Data are presented as means \pm SEM. *Statistical significance at $p<$ 0.05. C, Lane 1 shows a RAP ligand blot of uninjured sciatic nerve extract (50 $\mu \mathrm{g})$. This blot is representative of results obtained with uninjured nerve extracts from three individual rats. Lane 2 is a positive control in which we subjected extracts of LRP-1-positive PEA-10 cells to RAP ligand blotting. Lane 3 is a negative control in which we subjected LRP-1-deficient MEF-2 cell extracts to RAP ligand blotting.

injury, the cellular distribution of LRP-1, distal to the injury site, changed. Axonal LRP-1 was less abundant, whereas Schwann cell LRP-1 became more pronounced. Despite the loss of axonal LRP-1 antigen, LRP-1 mRNA in the distal injured nerve increased significantly, reflecting increased expression by Schwann cells. The equivalent result was demonstrated in three distinct model systems (crush, CCI, and axotomy) and in two species (rats and mice). LRP-1 expression was maximally increased at times after injury when Schwann cells are known to be activated (Wagner and Myers, 1996; Campana et al., 2006) and before the period when macrophages are recruited to the endoneurium (Sommer et al., 1995; Stoll et al., 2002).

LRP-1 expression by Schwann cells in injured nerve was regulated at least in part by TNF- $\alpha$ because the increase in LRP-1 post-CCI was significantly abated in the TNF- $\alpha$ gene knock-out mouse. Furthermore, direct injection of TNF- $\alpha$ into the CCI site in TNF- $\alpha$ gene knock-out mice increased LRP-1 expression. We confirmed the ability of TNF- $\alpha$ to increase LRP-1 expression in Schwann cells in culture. This is important because TNF- $\alpha$ or- chestrates many of the programmed events occurring in peripheral nerve injury (Stoll et al., 2002). The effects of TNF- $\alpha$ on LRP-1 expression have not been reported previously. Interferon- $\gamma$ shuts down LRP-1 expression in macrophages by regulating transcription (LaMarre et al., 1991; Hussaini et al., 1996). In the CNS, disorders associated with inflammation increase LRP-1 expression in astrocytes (Rebeck et al., 1993; Lopes et al., 1994). LRP-1 may facilitate astrocyte activation because the LRP-1 antagonist, RAP, inhibits astrocyte activation in culture (LaDu et al., 2001).

Our analysis of gene knock-out mice suggested that TNF- $\alpha$ regulates Schwann cell LRP-1 expression by activating TNFRII. TNFRII, but not TNFRI, is markedly upregulated in sciatic nerve $1 \mathrm{~d}$ after crush injury or CCI (George et al., 2005). The function of TNFRII is less well understood than TNFRI; however, the former receptor demonstrates mitogenic and proinflammatory activity in the immune response (Carpentier et al., 2004). TNFRII also has been implicated in neuronal survival (Shen et al., 1997; Yang et al., 2002). The function of LRP-1 in Schwann cell survival, demonstrated here, and the linkage of TNFRII to LRP-1 expression suggests that TNFRII plays an essential role in glial survival.

The increase in Schwann cell LRP-1 expression in adult nerve injury raised the hypothesis that LRP-1 is involved in autocrine cell-signaling pathways known to promote cell survival. In immature Schwann cells, which are known to die in response to nerve injury, LRP-1 failed to increase, supporting this hypothesis. To test the role of LRP-1 in Schwann cell survival, we first conducted experiments using primary Schwann cell cultures. A genesilencing approach was applied. Greater than $90 \%$ silencing was observed, which was important because this allowed us to conduct experiments without applying cell-sorting methods that may be difficult with primary cultures. Cells that were transfected with NTC siRNA served as a control. When cultured in complete medium, LRP-1-deficient Schwann cells appeared normal. No change in morphology or cell death was observed. However, when these cells were subjected to serum withdrawal or treated with TNF- $\alpha$, greatly increased cell death was observed. These results suggest that LRP-1 responds to stress and protects Schwann cells in culture from cell death. Because, the protective activity of LRP-1 was observed in response to serum deprivation and TNF- $\alpha$, we favored a model in which the pro-survival activity of LRP-1 is generalized and not specific to one apoptosisinducing agent or condition.

LRP-1 regulates cell signaling by binding adaptor proteins that may be involved in activation of enzymes, by sequestering cell signaling proteins and changing their subcellular distribution, and by altering the activity of other cell-signaling receptors, such as the urokinase receptor (Strickland et al., 2002). By binding Dab-1, receptors that are closely related to LRP-1 have been shown to activate PI3K (Bock et al., 2003). In this study, we showed that silencing LRP-1 in Schwann cells decreases the basal level of PI3K activity. LRP-1 gene-silencing also increased the level of activated caspase-3, detected in response to serum withdrawal and TNF- $\alpha$. These results suggest that the pro-survival activity of LRP-1 may be attributable to activation of the PI3KAkt pathway. In all of our LRP-1 gene-silencing experiments, we used pooled nontargeting siRNA as a control; however, we recognized that although LRP-1-silencing with siRNA L1 and siRNA L2 was extensive, it was not complete. Furthermore, treating cells with any siRNA (specific or control) involves exposure to transfection reagent. Thus, we considered it very important to confirm our observations regarding LRP-1 and the PI3K-Akt pathway using a second model system in which transfection is not necessary. For this reason, we studied MEFs and demonstrated the 
equivalent changes in Akt phosphorylation and caspase-3 activation when LRP-1 was deficient. LRP-1-deficient MEFs also showed increased susceptibility to TNF- $\alpha$.

Other mechanisms may exist by which LRP-1 functions in cell survival. In neurons, a chimeric receptor that contains the intracytoplasmic tail of LRP-1 promotes cell survival by preventing translocation of activated JNK to the nucleus (Lutz et al., 2002). By a similar mechanism, LRP-1 may control expression of the type-3 collagen gene (Gaultier et al., 2006). Our data do not allow us to rule out a contribution by the JNK pathway or other LRP1-regulated mechanisms in Schwann cell survival; however, our previous studies and work by others have demonstrated an important role for Akt as an established antiapoptotic signaling molecule required for Schwann cell survival (Campana et al., 1999; Li et al., 2003). Thus, the role of LRP-1 in controlling the $\mathrm{PI} 3 \mathrm{~K}-$ Akt pathway is particularly consistent with the current understanding of antiapoptotic signaling in Schwann cells.

Finally, we sought evidence that our hypothesis regarding the function of LRP-1 as a pro-survival Schwann cell receptor is significant in vivo. To accomplish this goal, we injected RAP directly into nerve fascicles immediately before axotomy. RAP binds LRP-1 in vivo and antagonizes the interaction with other ligands; however, RAP itself may be rapidly cleared by LRP-1-mediated endocytosis, which is why we chose local injection over systemic administration (Mettenburg et al., 2002). RAP caused a significant increase in cell death locally in the endoneurium of severed nerves, as determined by TUNEL; however, the total number of DAPI-positive cells was not significantly altered. Schwann cell proliferation and death are tightly linked during development and after nerve injury (Jessen and Mirsky, 2005). Thus, it is possible that RAP induced some degree of compensatory Schwann cell proliferation to offset death. Alternatively, the effects of RAP on cell death may have been slow enough that significant cell drop-out did not occur within $24 \mathrm{~h}$. In separate experiment, we determined that the number of ED-1 positive cells was not increased in RAP-treated nerves (data not shown), suggesting that RAP does not regulate macrophage recruitment.

The mechanism by which RAP regulates Schwann cell survival in vivo remains to be determined. There is considerable evidence that ligands regulate LRP-1-dependent signaling either by inducing LRP-1 homodimers or by cross-linking LRP-1 to other signaling receptors, such as the urokinase receptor (Bacskai et al., 2000; Webb et al., 2001; Hu et al., 2006). The mode of action of RAP probably involves disruption these interactions.

Our results indicating that LRP-1 is upregulated by TNF- $\alpha$ and that LRP-1 then counteracts the death-promoting effects of TNF- $\alpha$ may seem paradoxical; however, it is possible that LRP-1 functions as a negative-feedback switch, counteracting TNF- $\alpha$ in a time-dependent manner. It is also possible that LRP-1 endows Schwann cells with relative resistance to TNF- $\alpha$ in the dynamic multicellular microenvironment of the injured peripheral nerve. Finally, given the pleiotropic nature of TNF- $\alpha$, it is possible that LRP-1 regulates how the cell responds to this cytokine, dampening certain cell-signaling responses without affecting others. These possibilities are topics for future study.

In conclusion, we have shown that LRP-1 is expressed in the peripheral nervous system and abundantly in Schwann cells in nerve injury. LRP-1 expression is increased by TNF- $\alpha$ in vitro and in vivo. These results are particularly important in light of our data supporting the hypothesis that LRP-1 is a pro-survival receptor in Schwann cells. This activity is at least partially explained by the ability of LRP-1 to regulate cell signaling pathways that lead to the activation of PI3K.

\section{References}

Anitha M, Gondha C, Sutliff R, Parsadanian A, Mwangi S, Sitaraman SV, Srinivasan S (2006) GDNF rescues hyperglycemia-induced diabetic enteric neuropathy through activation of the PI3K/Akt pathway. J Clin Invest 116:344-356.

Asbury AK, Johnson TC (1978) Pathology of peripheral nerve, pp 256-249. Philadelphia, PA: Saunders.

Bacskai BJ, Xia MQ, Strickland DK, Rebeck GW, Hyman BT (2000) The endocytic receptor protein LRP also mediates neuronal calcium signaling via N-methyl-D-aspartate receptors. Proc Natl Acad Sci USA 97:11551-11556.

Bennett GJ, Xie YK (1988) A peripheral mononeuropathy in rat that produces disorders of pain sensation like those seen in man. Pain 33:87-107.

Bock HH, Jossin Y, Liu P, Forster E, May P, Goffinet AM, Herz J (2003) Phosphatidylinositol 3-kinase interacts with the adaptor protein Dab1 in response to Reelin and is required for normal cortical lamination. J Biol Chem 278:38772-38779.

Boyle K, Azari MF, Cheema SS, Petratos S (2005) TNFalpha mediates Schwann cell death by upregulating p75NTR expression without sustained activation of NF $\kappa$ B. Neurobiol Dis 20:412-427.

Brunet A, Datta SR, Greenberg ME (2001) Transcription-dependent and -independent control of neuronal survival by the PI3K-Akt signaling pathway. Curr Opin Neurobiol 11:297-305.

Campana WM, Myers RR (2001) Erythropoietin and erythropoietin receptors in the peripheral nervous system: changes after nerve injury. FASEB J 15:1804-1806.

Campana WM, Myers RR (2003) Exogenous erythropoietin protects against dorsal root ganglion apoptosis and pain following peripheral nerve injury. Eur J Neurosci 18:1497-1506.

Campana WM, Hiraiwa M, O’Brien JS (1998) Prosaptide activates the MAPK pathway by a G-protein-dependent mechanism essential for enhanced sulfatide synthesis by Schwann cells. FASEB J 12:307-314.

Campana WM, Darin SJ, O’Brien JS (1999) Phosphatidylinositol 3-kinase and Akt protein kinase mediate IGF-I- and prosaptide-induced survival in Schwann cells. J Neurosci Res 57:332-341.

Campana WM, Li X, Shubayev V, Angert M, Myers RR (2006) Erythropoietin reduces TNF-alpha expression, Wallerian degeneration and painful behaviors after peripheral nerve injury. Eur J Neurosci 23:617-626.

Carpentier I, Coornaert B, Beyaert R (2004) Function and regulation of tumor necrosis factor receptor type 2. Curr Med Chem 11:2205-2212.

Gaultier A, Salicioni AM, Arandjelovic S, Gonias SL (2006) Regulation of the composition of the extracellular matrix by low density lipoprotein receptor-related protein-1. J Biol Chem 281:7332-7340.

George A, Buehl A, Sommer C (2005) Tumor necrosis factor receptor 1 and 2 proteins are differentially regulated during Wallerian degeneration in mouse sciatic nerve. Exp Neurol 192:163-166.

Gonias SL, Wu L, Salicioni AM (2004) Low density lipoprotein receptorrelated protein: regulation of the plasma membrane proteome. Thromb Haemost 91:1056-1064.

Gotthardt M, Trommsdorff M, Nevitt MF, Shelton J, Richardson JA, Stockinger W, Nimpf J, Herz J (2000) Interactions of the low density lipoprotein receptor gene family with cytosolic adaptor and scaffold proteins suggest diverse biological functions in cellular communication and signal transduction. J Biol Chem 275:25616-25624.

Grinspan JB, Marchionni MA, Reeves M, Coulaloglou M, Scherer SS (1996) Axonal interactions regulate Schwann cell apoptosis in developing peripheral nerve: neuregulin receptors and the role of neuregulins. J Neurosci 16:6107-6118.

Herz J, Goldstein JL, Strickland DK, Ho YK, Brown MS (1991) 39-kDa protein modulates binding of ligands to low density lipoprotein receptorrelated protein/alpha 2-macroglobulin receptor. J Biol Chem 266:21232-21238.

Herz J, Clouthier DE, Hammer RE (1992) LDL receptor-related protein internalizes and degrades uPA-PAI-1 complexes and is essential for embryo implantation. Cell 71:411-421.

Hiraiwa M, Taylor EM, Campana WM, Darin SJ, O’Brien JS (1997) Cell death prevention, mitogen-activated protein kinase stimulation, and increased sulfatide concentrations in Schwann cells and oligodendrocytes by prosaposin and prosaptides. Proc Natl Acad Sci USA 94:4778-4781.

Hu K, Yang J, Tanaka S, Gonias SL, Mars WM, and Liu Y 2006 Tissue-type plasminogen activator acts as a cytokine that triggers intracellular signal 
transduction and induces matrix metalloprotease-9 expression. J Biol Chem 281:2120-2127.

Hussaini IM, LaMarre J, Lysiak JJ, Karns LR, VandenBerg SR, Gonias SL (1996) Transcriptional regulation of LDL receptor-related protein by IFN-gamma and the antagonistic activity of TGF-beta(1) in the RAW 264.7 macrophage-like cell line. J Leukoc Biol 59:733-739.

Jessen KR, Mirsky R (2005) The origin and development of glial cells in peripheral nerves. Nat Rev Neurosci 6:671-682.

Jessen KR, Morgan L, Stewart HJ, Mirsky R (1990) Three markers of adult non-myelin-forming Schwann cells, 217c(Ran-1), A5E3 and GFAP: development and regulation by neuron-Schwann cell interactions. Development 109:91-103.

Kinoshita A, Whelan CM, Smith CJ, Mikhailenko I, Rebeck GW, Strickland DK, Hyman BT (2001) Demonstration by fluorescence resonance energy transfer of two sites of interaction between the low-density lipoprotein receptor-related protein and the amyloid precursor protein: role of the intracellular adapter protein Fe65. J Neurosci 21:8354-8361.

Kowal RC, Herz J, Goldstein JL, Esser V, Brown MS (1989) Low density lipoprotein receptor-related protein mediates uptake of cholesteryl esters derived from apoprotein E-enriched lipoproteins. Proc Natl Acad Sci USA 86:5810-5814.

LaDu MJ, Shah JA, Reardon CA, Getz GS, Bu G, Hu J, Guo L, Van Eldik LJ (2001) Apolipoprotein E and apolipoprotein E receptors modulate A beta-induced glial neuroinflammatory responses. Neurochem Int 39:427-434.

LaMarre J, Wollenberg GK, Gonias SL, Hayes MA (1991) Reaction of alpha 2-macroglobulin with plasmin increases binding of transforming growth factors-beta 1 and beta 2. Biochim Biophys Acta 1091:197-204.

Li XQ, Gonias SL, Campana WM (2005) Schwann cells express erythropoietin receptor and represent a major target for Epo in peripheral nerve injury. Glia 51:254-265.

Li Y, Gonzalez MI, Meinkoth JL, Field J, Kazanietz MG, Tennekoon GI (2003) Lysophosphatidic acid promotes survival and differentiation of rat Schwann cells. J Biol Chem 278:9585-9591.

Ling TY, Chen CL, Huang YH, Liu IH, Huang SS, Huang JS (2004) Identification and characterization of the acidic $\mathrm{pH}$ binding sites for growth regulatory ligands of low density lipoprotein receptor-related protein-1. J Biol Chem 279:38736-38748.

Livak KJ, Schmittgen TD (2001) Analysis of relative gene expression data using real-time quantitative PCR and the $2^{-\Delta \Delta C_{T}}$ Method. Methods 25:402-408.

Lopes MB, Bogaev CA, Gonias SL, VandenBerg SR (1994) Expression of alpha 2-macroglobulin receptor/low density lipoprotein receptor-related protein is increased in reactive and neoplastic glial cells. FEBS Lett 338:301-305.

Lutz C, Nimpf J, Jenny M, Boecklinger K, Enzinger C, Utermann G, BaierBitterlich G, Baier G (2002) Evidence of functional modulation of the $\mathrm{MEKK} / \mathrm{JNK} / \mathrm{cJun}$ signaling cascade by the low density lipoprotein receptor-related protein (LRP). J Biol Chem 277:43143-43151.

Macdonald R, Bingham S, Bond BC, Parsons AA, Philpott KL (2001) Determination of changes in mRNA expression in a rat model of neuropathic pain by Taqman quantitative RT-PCR. Brain Res Mol Brain Res 90:48-56.

Medh JD, Fry GL, Bowen SL, Plaet MW, Strickland DK, Chappell DA (1995) The 39-kDa receptor-associated protein modulates lipoprotein catabolism by binding to LDL receptors. J Biol Chem 270:536-540.

Meier C, Parmantier E, Brennan A, Mirsky R, Jessen KR (1999) Developing Schwann cells acquire the ability to survive without axons by establishing an autocrine circuit involving insulin-like growth factor, neurotrophin-3, and platelet-derived growth factor-BB. J Neurosci 19:3847-3859.

Mettenburg JM, Webb DJ, Gonias SL 2002 Distinct binding sites in the structure of alpha 2-macroglobulin mediate the interaction with $\beta$-amyloid peptide and growth factors. J Biol Chem 277:13338-13345.

Moestrup SK, Gliemann J, Pallesen G (1992) Distribution of the alpha 2-macroglobulin receptor/low density lipoprotein receptor-related protein in human tissues. Cell Tissue Res 269:375-382.

Myers RR, Yamamoto T, Yaksh TL, Powell HC (1993) The role of focal nerve ischemia and Wallerian degeneration in peripheral nerve injury producing hyperesthesia. Anesthesiology 78:308-316.

Myers RR, Sekiguchi Y, Kikuchi S, Scott B, Medicherla S, Protter A, Campana WM (2003) Inhibition of p38 MAP kinase activity enhances axonal regeneration. Exp Neurol 184:606-614.
Newton CS, Loukinova E, Mikhailenko I, Ranganathan S, Gao Y, Haudenschild C, Strickland DK (2005) Platelet-derived growth factor receptorbeta (PDGFR-beta) activation promotes its association with the low density lipoprotein receptor-related protein (LRP). Evidence for co-receptor function. J Biol Chem 280:27872-27878.

Pfaffl MW (2001) A new mathematical model for relative quantification in real-time RT-PCR. Nucleic Acids Res 29:e45.

Rebeck GW, Reiter JS, Strickland DK, Hyman BT (1993) Apolipoprotein E in sporadic Alzheimer's disease: allelic variation and receptor interactions. Neuron 11:575-580.

Shamash S, Reichert F, Rotshenker S (2002) The cytokine network of Wallerian degeneration: tumor necrosis factor- $\alpha$, interleukin- $1 \alpha$, and interleukin-1 $\beta$. J Neurosci 22:3052-3060.

Shen Y, Li R, Shiosake K (1997) Inhibition of p75 tumor necrosis factor receptor by antisense oligonucleotides increases hypoxic injury and $\beta$-amyloid toxicity in human nueronal cell line. J Biol Chem 272:3550-3553.

Shubayer VI, Angert M, Dolkas J, Campana WM, Palenscar K, Myers RR (2006) TNF $\alpha$-induced MMP-9 promotes macrophage recruitment into injured peripheral nerve.

Sommer C, Lalonde A, Heckman HM, Rodriguez M, Myers RR (1995) Quantitative neuropathology of a focal nerve injury causing hyperalgesia. J Neuropathol Exp Neurol 54:635-643.

Stoll G, Jander S, Myers RR (2002) Degeneration and regeneration of the peripheral nervous system: from Augustus Waller's observations to neuroinflammation. J Peripher Nerv Syst 7:13-27.

Strickland DK, Ashcom JD, Williams S, Burgess WH, Migliorini M, Argraves WS (1990) Sequence identity between the alpha 2-macroglobulin receptor and low density lipoprotein receptor-related protein suggests that this molecule is a multifunctional receptor. J Biol Chem 265:17401-17404.

Strickland DK, Gonias SL, Argraves WS (2002) Diverse roles for the LDL receptor family. Trends Endocrinol Metab 13:66-74.

Su HP, Nakada-Tsukui K, Tosello-Trampont AC, Li Y, Bu G, Henson PM, Ravichandran KS (2002) Interaction of CED-6/GULP, an adapter protein involved in engulfment of apoptotic cells with CED-1 and CD91/low density lipoprotein receptor-related protein (LRP). J Biol Chem 277:11772-11779.

Syroid DE, Maycox PJ, Soilu-Hanninen M, Petratos S, Bucci T, Burrola P, Murray S, Cheema S, Lee KF, Lemke G, Kilpatrick TJ (2000) Induction of postnatal Schwann cell death by the low-affinity neurotrophin receptor in vitro and after axotomy. J Neurosci 20:5741-5747.

Thorburn A (2004) Death receptor-induced cell killing. Cell Signal 16:139-144.

Wagner R, Myers RR (1996) Schwann cells produce tumor necrosis factor alpha: expression in injured and non-injured nerves. Neuroscience 73:625-629.

Webb DJ, Thomas KS, Gonias SL (2001) Plasminogen activator inhibitor-1 functions as a urokinase response modifier at the level of cell signaling and thereby promotes MCF-7 cell growth. J Cell Biol 152:741-751.

Williams SE, Aschim JD, Argraves WS, Strickland DK (1992) A novel mechanism for controlling the activity of alpha 2 macroglobulin receptor/low density lipoprotein receptor related protein: Multiple regulatory sites for $39 \mathrm{kDa}$ receptor-associated protein. J Biol Chem 267:9035-9040.

Willnow TE, Herz J (1994) Genetic deficiency in low density lipoprotein receptor-related protein confers cellular resistance to Pseudomonas exotoxin A. Evidence that this protein is required for uptake and degradation of multiple ligands. J Cell Sci 107:719-726.

Willnow TE, Moehring JM, Inocencio NM, Moehring TJ, Herz J (1996) The low-density-lipoprotein receptor-related protein (LRP) is processed by furin in vivo and in vitro. Biochem J 313:71-76.

Wolf BB, Lopes MB, VandenBerg SR, Gonias SL (1992) Characterization and immunohistochemical localization of alpha 2-macroglobulin receptor (low-density lipoprotein receptor-related protein) in human brain. Am J Pathol 141:37-42.

Wu L, Gonias SL (2005) The low-density lipoprotein receptor-related protein-1 associates transiently with lipid rafts. J Cell Biochem 96:1021-1033.

Yang L, Lindholm K, Konishi Y, Li R, Shen Y (2002) Target depletion of distinct tumor necrosis factor receptor subtypes reveals hippocampal neuron death and survival through different signal transduction pathways. J Neurosci 22:3025-3032. 